\section{Twice as natural}

\section{Richard E. Lenski}

A ccording to the book of Genesis, God made all life and "created man in his own image". It is no wonder, then, that humankind has long sought to create life of its own. But what is artificial life?

Setting aside for a moment the meaning of 'life' itself, the use of the word 'artificial' introduces its own quandary. Where does 'natural' end and 'artificial' begin? Thomas Browne, in Religio Medici (1642), said that "all things are artificial; for Nature is the Art of God". This view might seem to exclude science. But by emphasizing the artistry of creation, Browne encouraged the study of "Nature, that universal and publick Manuscript, that lies expans'd unto the eyes of all".

A radically different idea of artificial life appeared a few years later. In Leviathan (1651), Thomas Hobbes said that "Nature ... is by the Art of man ... imitated, that it can make an Artificial Animal". Just what sort of artificial animal did Hobbes have in mind, that humans could have created 350 years ago? In his view, the political state is a kind of super-organism, "an Artificiall Man; though of greater stature and strength than the Naturall, for whose protection and defence it

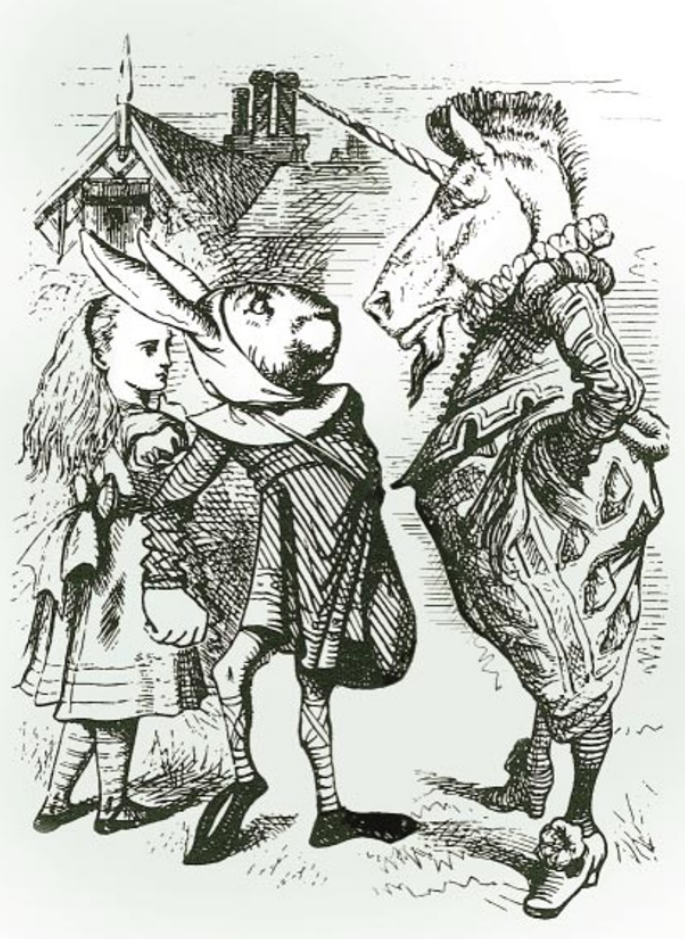

Monsters of the imagination: Lewis Carroll's Hare said that Alice was "twice as natural" as he imagined. Should we be similarly impressed by today's evolving artificial life-forms? was intended". To Hobbes, who sought to avoid anarchy, life in this artificial state is much better than the natural condition, in which life is "solitary, poore, nasty, brutish, and short".

Hobbes also wondered whether "all Automata (Engines that move themselves by springs and wheeles as doth a watch) have an artificiall life". It now seems quaint to suggest that a watch is alive because it can move itself. But where should we draw the line between animate and inanimate, between life and non-life? Is a robot that walks more alive than a ticking watch? What if the robot can think? What if it has emotions and drives? What if it can reproduce itself? HAL, the spaceship's computer in Arthur C. Clarke's novel 2001: A Space Odyssey, was intelligent and driven to self-preservation. Yet without the capacity to reproduce, would we say that HAL was alive?

The importance of reproduction for understanding life, even artificial life, found its way into William Paley's Natural Theology (1802), in which Paley advanced the creationist argument from design. According to this view, the intricate and interconnected features of organisms that suit them to their environments imply the existence of a creator, in the same way in which the intricately connected parts of a watch imply a watchmaker "who comprehended its construction and designed its use". Paley took the argument another step by asking the reader to imagine a watch that "possessed the unexpected property of producing, in the course of its movement, another watch like itself". (He remarked that "this thing is conceivable", although I doubt that the pun was intended.)

Paley thought that the capacity for self-replication should "increase beyond measure our admiration of the skill which had been employed in the formation of such a machine". He invoked his hypothetical watch to rebut the counter-argument that, although a watch has a watchmaker, organisms are made by their parents. For Paley, self-replication merely pushed back in time the actions of the creator. Humans have not yet created any entirely self-replicating robots, although one might reasonably view a self-replicating program - a computer virus - as alive in this sense.

Paley imagined descent without modification. Computer viruses, likewise, have no intrinsic capacity to evolve - new varieties are created by a few malicious hackers. Does self-replication without evolution constitute life, as understood by biologists today?

Charles Darwin was the first to grasp firmly the importance of descent with
Artificial life

The meaning of 'artificial life' has

evolved through the years. We

now have artificial life that can

itself evolve.

modification. He closed On the Origin of Species (1859) by saying that "from so simple a beginning endless forms most beautiful and wonderful have been, and are being, evolved". We now know that real organisms make heritable errors, or mutations, during selfreplication. Many mutations are harmful and are eliminated by natural selection, but some are fortuitously beneficial, thereby providing the raw material for evolutionary adaptation.

It is fortunate that computer viruses, so far, cannot spontaneously evolve. But other self-replicating computer programs are subject to copying errors. And these mutations allow populations of programs to evolve in, and adapt to, their operating environment. The biologist Tom Ray wrote the Tierra software with precisely this evolutionary potential in mind. He found that programs quickly evolved into more efficient replicators, including parasites that replicated themselves by exploiting others. Chris Adami, a physicist, and Charles Ofria, a computer scientist, then developed Avida, in which programs evolve a computational metabolism that is above and beyond their capacity to self-replicate.

Alas, these 'digital organisms' are not nearly as sophisticated as simple bacteria, or even real viruses. But then, artificial life has been around for only a few years. The natural stuff has been replicating, mutating and evolving for billions of years. Who knows what forms artificial life will take in a thousand, a million or a billion years?

Richard E. Lenski is in the Center for Biological Modeling and the Center for Microbial Ecology, Michigan State University, East Lansing,

Michigan 48824, USA.

\section{FURTHER READING}

Adami, C. Introduction to Artificial Life (Springer, New York, 1998).

Chao, L. BioScience 50, 245-250 (2000).

Ray, T. S. in Artificial Life Vol. 2 (eds Langton, C. G., Taylor, C. E., Farmer, J. D. \& Rasmussen, S.) 371-408 (Addison-Wesley, Redwood City, California, 1991). Wilke, C. 0., Wang, J., Ofria, C., Lenski, R. E. \& Adami, C. Nature 412, 331-333 (2001).

\section{WEBLINKS}

Digital Life Laboratory

http://dllab.caltech.edu/avida

Evolved virtual creatures

http://www.genarts.com/karl/evolved-virtualcreatures.html 